\title{
ABOUT ONE NUMERICAL METHOD FOR SOLVING DIRECT AND INVERSE PROBLEMS OF THE DYNAMIC MEASUREMENTS THEORY
}

Yu. S. Popenko, South Ural State University, Chelyabinsk, Russian Federation, popenkoyu@mail.ru.

The direct and inverse problems of measurement theory based on linear differential operator with the boundary conditions of various types were considered. The boundary conditions are linear and linear independent functionals (including Cauchy problem, twopoint boundary value problem, the Vallee-Poussin problem, the multipoint boundary value problems, the distributed data problems, and so on). An approach is proposed to investigate such problems on the basis of mathematical models realized in the form of linear boundary value problems and accompanying integral equations using the Green's function. The Green's functions, in the absence of information on the fundamental system of solutions of the corresponding differential equation, is constructed as a solution of the Fredholm integral equation of the second kind. The characteristics of the Fredholm equation were determined by the Green's function of the auxiliary problem. The proposed method allows to solve both the direct (the problem of finding solutions) and the inverse (the problem of finding the right-hand side of the equation from the experimentally obtained solution). The examples the work of programs realized in the system Mathematica 8.0 based on the described method were given.

Keywords: Green's function, nonlocal boundary conditions, measurements theory, dynamic measurements.

\section{Introduction}

This paper is devoted to study mathematical models of linear dynamic systems applied to the dynamic theory of measurements based on linear boundary value problems for ordinary differential equations.

Dynamic measurements is a branch of Metrology dealing with measurements using hardware with dynamic conditions [1]. These measurements concern, primarily, to the study of regularities of physical processes in the studied objects.

Dynamic measurements, in particular measurements of rapidly changing physical quantities, are one of the most important research tools in various fields of engineering and scientific research. Pressure surges, shock accelerations, a sharp change in speed of motion and spatial location are often encountered in practice. The main contribution to the dynamic error is made by the inertia of the measuring instruments, therefore it is justified to consider the problems of dynamic measurements in the class of linear problems [2].

Measurements in dynamic mode are widely used to improve the efficiency of technological processes in the time of testing new equipment, and also in scientific research. Only in Russia more than a million such measurements are carried out daily, using special measuring instruments, devices and systems [3].

\section{Statement of the Problem}

A wide class of problems of the dynamical measurements theory can be formulated in the form of linear boundary-value problems (including nonclassical conditions) for ordinary 
differential equations. Among them are multipoint boundary value problems, distributed data problems, and so on.

Consider a linear dynamical system:

$$
\left\{\begin{array}{l}
L[x]=f(t), \\
U_{j}(x)=\alpha_{j}, j=1,2, \ldots, n,
\end{array}\right.
$$

where $L[x]=x^{(n)}+p_{n-1} x^{(n-1)}+\cdots+p_{1} x^{\prime}+p_{0} x$, coefficients $p_{i}(t)$ are continuous functions on $[a, b], U_{j}(x)$ are linear, linearly independent functionals, $\alpha_{j}$ are constants.

The problem of finding the solution $x(t)$ of equation (1) for a given right-hand side $f(t)$ and given boundary conditions is called a direct problem.

The problem of finding the solution $f(t)$ of equation (1) with the experimentally known solution $x(t)$ and given boundary conditions is called an inverse problem.

\section{Method of Solution}

The linear boundary value problem (1) can be equivalently replaced [4] by some problem with homogeneous boundary conditions $\left(\alpha_{j}=0\right.$ for $\left.j=1,2, n\right)$, which we will call semihomogeneous:

$$
\left\{\begin{array}{l}
L[x]=\hat{f}(t), \\
U_{j}(x)=0, j=1,2, \ldots, n .
\end{array}\right.
$$

As for the boundary conditions, the theorem (the proof, for example, in [5]) of a general form of a linear functional is given below.

If $U(x)$ is a linear functional in $C_{[a ; b]}^{n-1}$, then the numbers $c_{i}$ and the function of bounded variation $\sigma(t)$ exist, and $U(x)$ can be represented in the following form:

$$
U(x)=\sum_{i=1}^{n} c_{i} x^{(i-1)}(a)+\int_{a}^{b} x^{(n-1)}(t) d \sigma(t) .
$$

The representation (3) is associated with the classical initial Cauchy problem. It is easy to show that for functionals $U(x)$ another representation associated with the simple Vallee-Poussin problem can be obtained:

$$
U(x)=\sum_{i=1}^{n} c_{i} x\left(t_{i}\right)+\int_{a}^{b} x^{(n-1)}(t) d \sigma(t),
$$

where $t_{i}$ are points from the interval $[a, b]$, such that $a \leq t_{1}<t_{2}<\cdots<t_{n} \leq b$.

The proposed methods for solving the investigated problems use the Green's function and are based on the well-known (for example, [6]) relationship, which gives the solution of the semihomogeneous boundary value problem (2) in the integral form:

$$
x(t)=\int_{a}^{b} G(t, \tau) f(\tau) d \tau,
$$

where $G(t, \tau)$ is the Green's function of the considered problem.

As the relation (5) shows, if the Green's function of problem (2) is known, the solution of the direct problem reduces to calculation of the quadrature (5). At the same time, the 
accuracy of the obtained solution is determined by the accuracy of the measurements of the right-hand side and can easily be estimated.

The solution of the inverse problem represents the considering the relation (5) as an integral equation with unknown function $f(t)$ for a given function $x(t)$. It is a Fredholm equation of the first kind and, as is well known (for example, [7]), the problem of solving such equation is unstable for the errors of the left side of the equation (5). So, this requires a special procedure of regularization to ensure a satisfactory for applications accuracy of the obtained solution.

The construction of the Green's function is an important part of the proposed method. The method for constructing the Green's function for a general linear boundary value problem was proposed in [8] and developed in the papers [4, 9, 10]. The method consists in constructing an auxiliary integral equation that allows to find the Green's function of the problem (2) for arbitrary (including nonclassical) boundary conditions, even when the fundamental system of solutions of the equation (1) can not be found (or can not be used for other reasons).

The main part of the described method is the construction of the Green's function $G(t, \tau)$, carried out in two stages, first, the construction of the Green's function $\tilde{G}(t, \tau)$ of the auxiliary problem

$$
\left\{\begin{array}{l}
x^{(n)}=f(t), \\
U_{j}(x)=0, j=1,2, \ldots, n,
\end{array}\right.
$$

that can be found directly by definition using the fundamental system of solutions of the corresponding homogeneous equation. The second step is to find numerically the Green function of the basic problem $G(t, \tau)$, that is a solution of the Fredholm integral equation of the second kind:

$$
G(t, s)-\tilde{G}(t, s)=\int_{a}^{b} G(t, \tau) V(\tau, s) d \tau .
$$

More details can be found in $[4,9,10]$.

\section{Computer Realization}

On the basis of this numerical method, algorithms for solving direct and inverse problems of the dynamic measurements theory were developed [11]. The proposed algorithms were realized as a complex of computer programs using the Mathematica 8.0. It includes two programs:

- The Program for Finding the Numerical Solution of the Direct Problem of the Measurements Theory ${ }^{1}$.

- The Program for Finding the Numerical Solution of the Inverse Problem of the Measurements Theory ${ }^{2}$.

Further the examples of programs executions were given.

\footnotetext{
${ }^{1}$ Certificate of official registration of the computer program № 2013618951.

${ }^{2}$ Certificate of official registration of the computer program № 2012619481.
} 


\section{Examples}

\section{Example 1.}

Consider the following linear boundary value problem:

$$
\left\{\begin{array}{l}
x^{\prime \prime \prime}-2 x^{\prime \prime}-5 x^{\prime}+6 x=\sin 10 t+\cos 5 t \\
x(0)=0, x^{\prime}(0)=0, x^{\prime \prime}(0)=0
\end{array}\right.
$$

The function on the right-hand side of the differential equation $f(t)=\sin (10 t)+\cos (5 t)$ is given with an error, i.e. $\tilde{f}(t)=\sin (10 t)+\cos (5 t)+\varepsilon(t)$. The plot of the unperturbed function $f(t)$ and function of initial data $\tilde{f}(t)$ is shown in Fig. 1.

According to the algorithm for solving the problem, first, the Green's function of the auxiliary problem is found. Its graph is presented in Fig. 3. Next the Green's function of the main problem is found. Its graph is presented in Fig. 4. Then the solution of the original problem is found. It is represented in Fig. 2.

The absolute error of the obtained solution is $\delta_{a}=0.00196$, the relative error is $\delta=1.7 \%$. The operating time of the program is $T=3.2$ seconds.

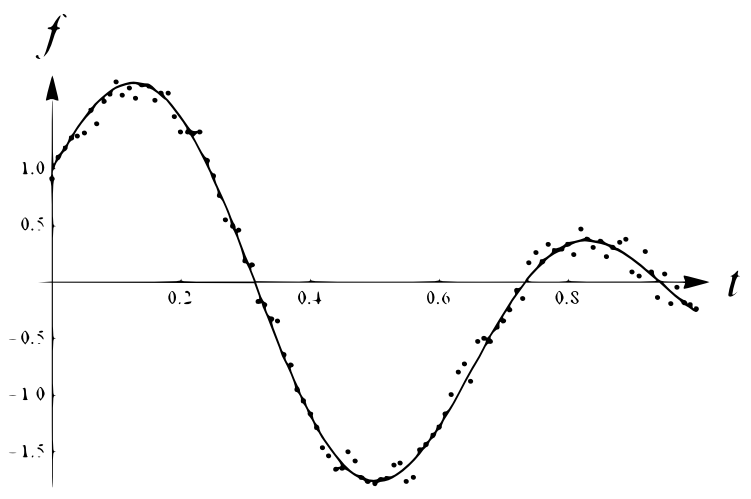

Fig. 1. The exact function of the initial data $f(t)$ (solid), the given perturbed function of the initial data $\tilde{f}(t)$ (points)

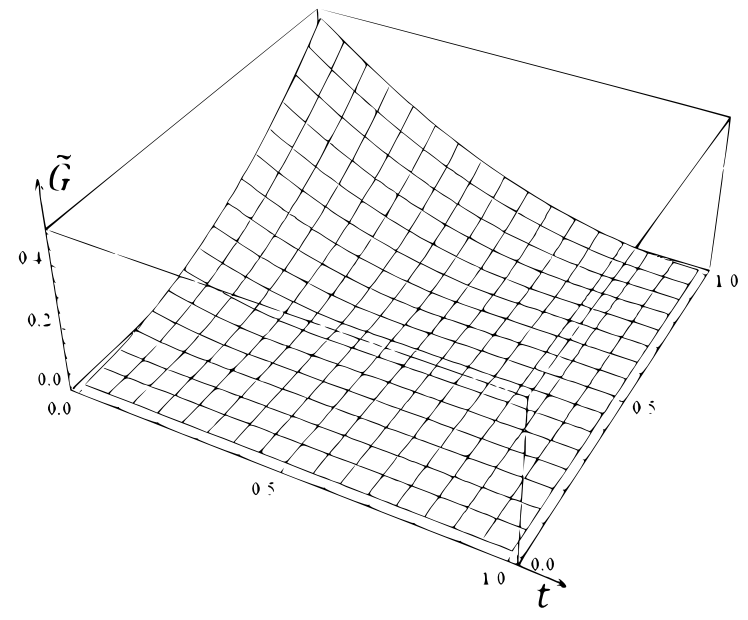

Fig. 3. The Green's function $\tilde{G}(t, \tau)$ of the auxiliary problem

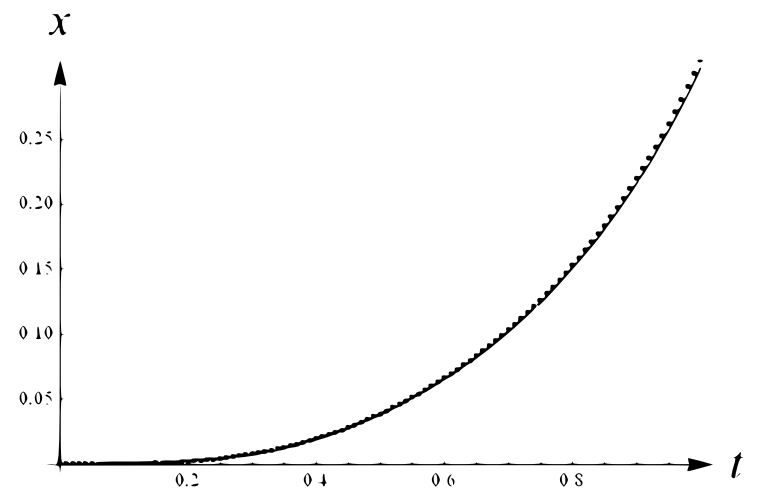

Fig. 2. The exact function of the solution $x_{0}(t)$ (solid), the obtained function of the solution $x(t)$ (points)

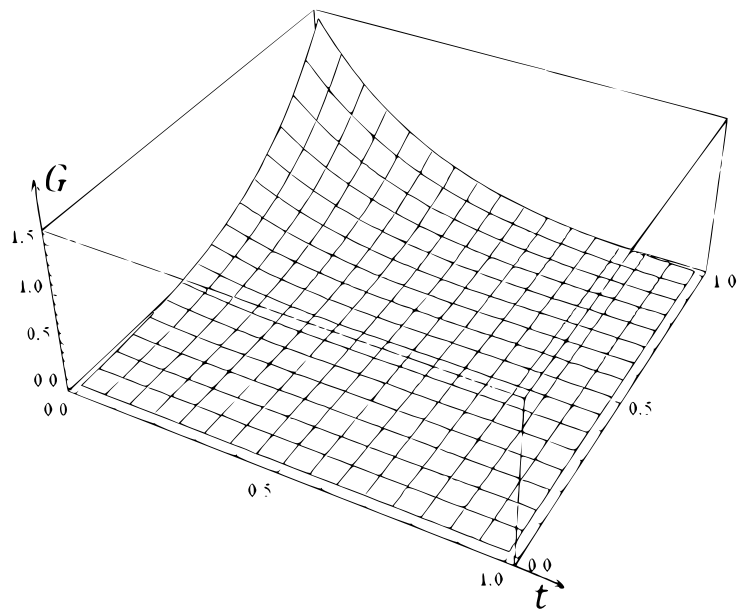

Fig. 4. The Green's function $G(t, \tau)$ of the main problem 


\section{Example 2.}

Consider the following linear boundary value problem:

$$
\left\{\begin{array}{l}
x^{\prime \prime \prime}-2 x^{\prime \prime}-5 x^{\prime}+6 x=\sin 10 t+\cos 5 t \\
x(0)=0, x(0,5)=0, x(0)=0
\end{array}\right.
$$

The function on the right-hand side of the differential equation $f(t)=\sin (10 t)+\cos (5 t)$ is given with an error, i.e. $\tilde{f}(t)=\sin (10 t)+\cos (5 t)+\varepsilon(t)$. The plot of the unperturbed function $f(t)$ and function of initial data $\tilde{f}(t)$ is shown in Fig. 5 .

According to the algorithm for solving the problem, first, the Green's function of the auxiliary problem is found. Its graph is presented in Fig. 7. Next the Green's function of the main problem is found. Its graph is presented in Fig. 8. Then the solution of the original problem is found. It is represented in Fig. 6.

The absolute error of the obtained solution is $\delta_{a}=0.000058$, the relative error is $\delta=1.7 \%$. The operating time of the program is $T=12.1$ seconds.

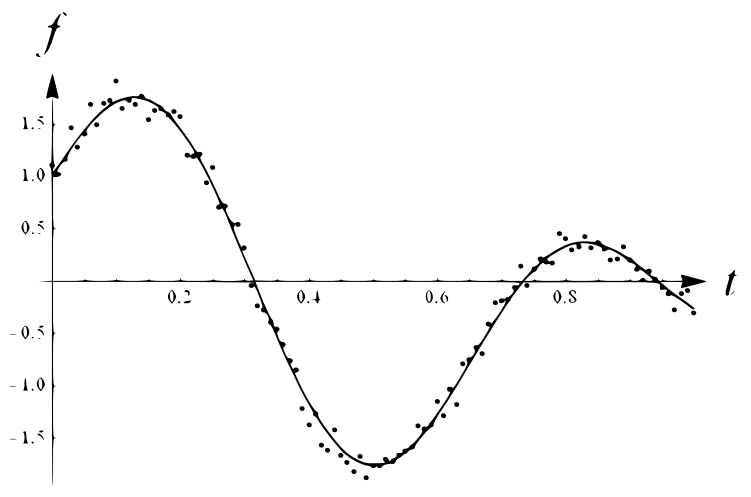

Fig. 5. The exact function of the initial data $f(t)$ (solid), the given perturbed function of the initial data $\tilde{f}(t)$ (points)

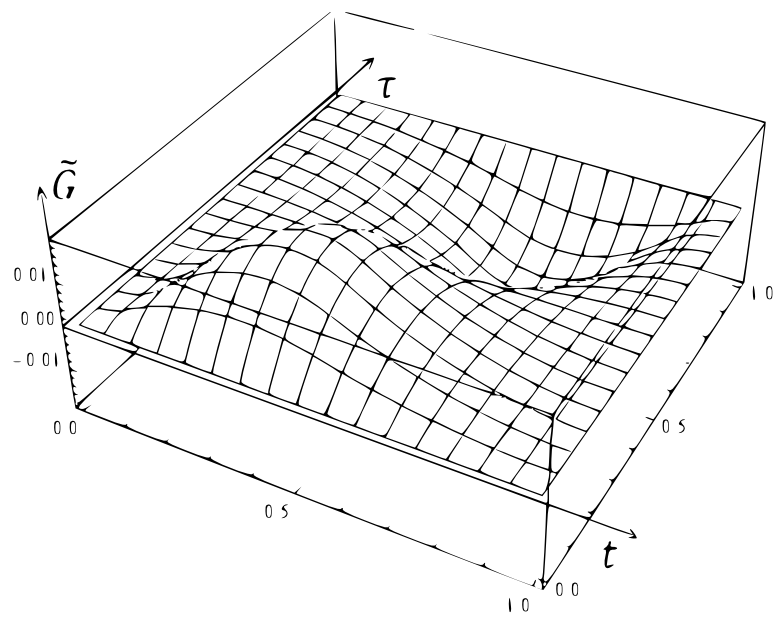

Fig. 7. The Green's function $\tilde{G}(t, \tau)$ of the auxiliary problem

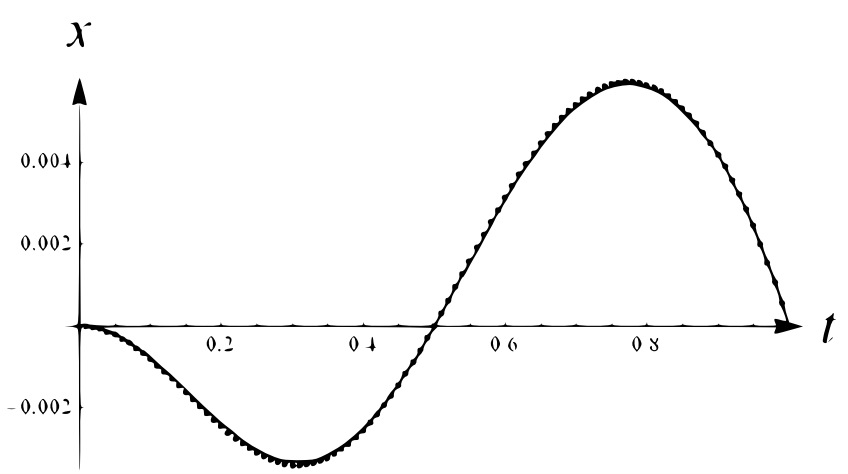

Fig. 6. The exact function of the solution $x_{0}(t)$ (solid), the obtained function of the solution $x(t)$ (points)

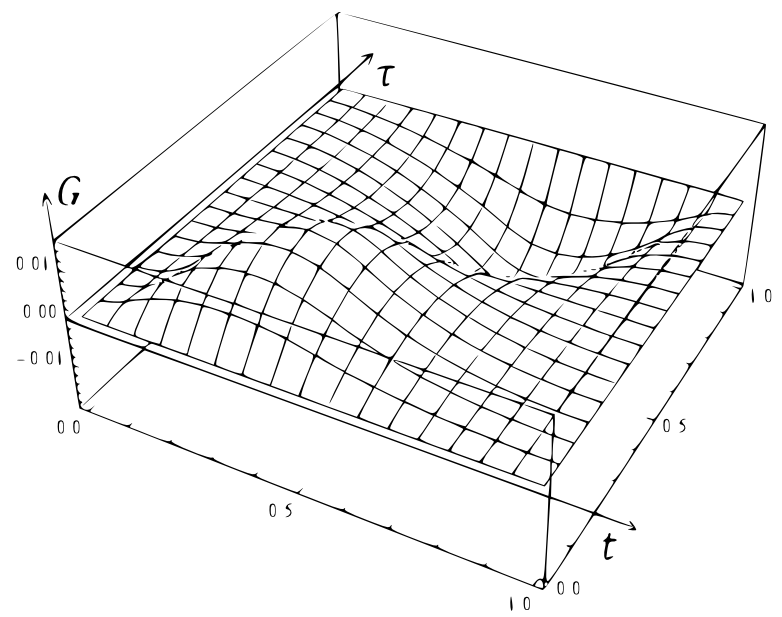

Fig. 8. The Green's function $G(t, \tau)$ of the main problem 
Example 3. Consider the following linear boundary value problem:

$$
\left\{\begin{array}{l}
x^{\prime \prime \prime}-2 x^{\prime \prime}-5 x^{\prime}+6 x=\sin 10 t+\cos 5 t \\
\int_{0}^{1} x(t) d t=0,004, \int_{0}^{1} t x(t) d t=-0,001, \int_{0}^{1} t^{2} x(t) d t=0,003 .
\end{array}\right.
$$

The function on the right-hand side of the differential equation $f(t)=\sin (10 t)+\cos (5 t)$ is given with an error, i.e. $\tilde{f}(t)=\sin (10 t)+\cos (5 t)+\varepsilon(t)$. The plot of the unperturbed function $f(t)$ and function of initial data $\tilde{f}(t)$ is shown in Fig. 9.

Since the considered problem is an inhomogeneous, first it must be transformed to homogeneous form. In this case, the function $f(t)$ on the right-hand side of the differential equation will be reduced to the form $\hat{f}(t)$ corresponding to the semihomogeneous problem. The plot of the function $\hat{f}(t)$ is represented in Fig. 10 .

Further, according to the algorithm for solving the problem, first, the Green's function of the auxiliary problem is found. Its graph is presented in Fig. 12. Next the Green's function of the main problem is found. Its graph is presented in Fig. 13. Then the solution of the original problem is found. It is represented in Fig. 11.

The absolute error of the obtained solution is $\delta_{a}=0.000121899$, the relative error is $\delta=0.2 \%$. The operating time of the program is $T=22.8$ seconds.

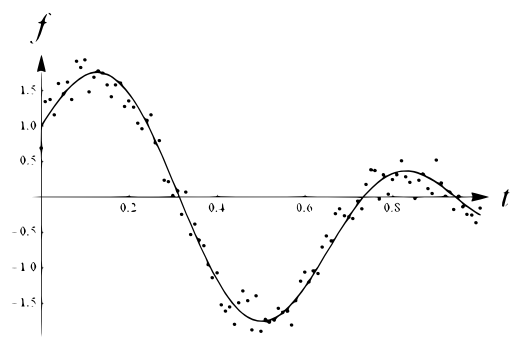

Fig. 9. The exact function of the initial data $f(t)$ (solid), the given perturbed function of the initial data $\tilde{f}(t)$ (points)

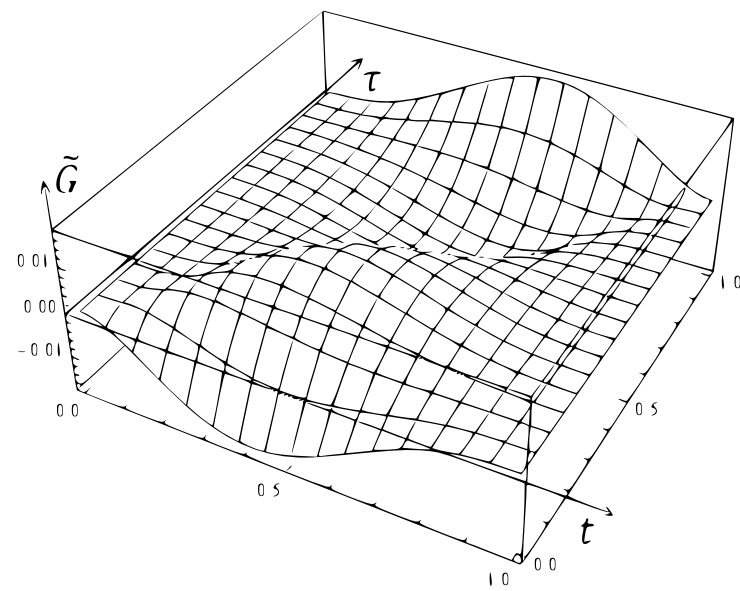

Fig. 12. The Green's function $\tilde{G}(t, \tau)$ of the auxiliary problem

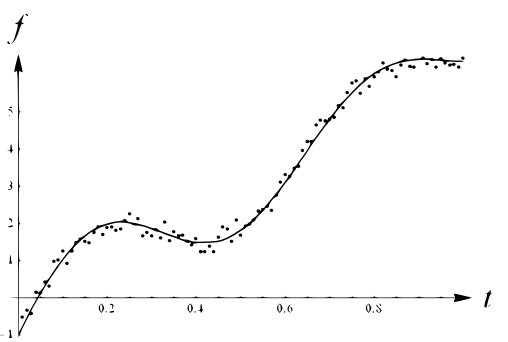

Fig. 10. The exact function $\hat{f}(t) \quad$ (solid) and perturbed function of the homogeneous problem $\check{f}(t)$ (points)

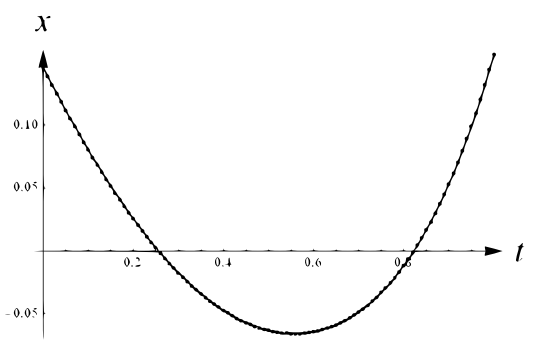

Fig. 11. The exact function of the solution $x_{0}(t)$ (solid), the obtained function of the solution $x(t)$ (points)

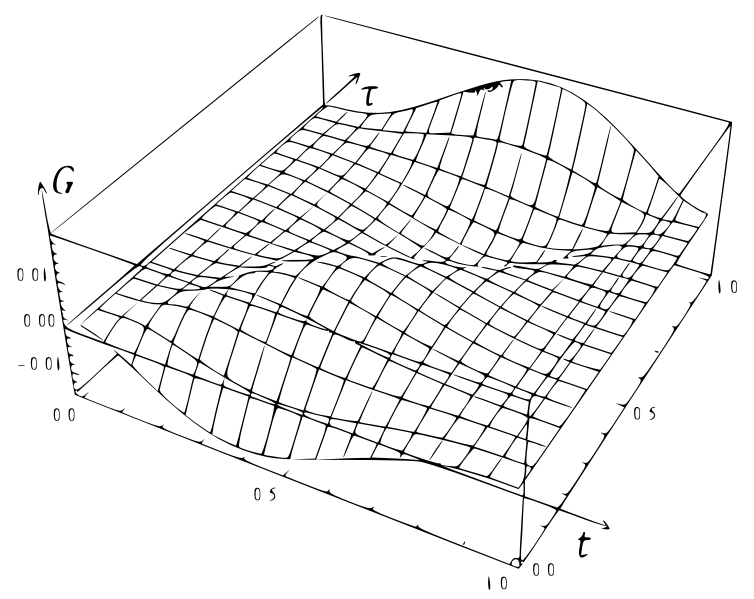

Fig. 13. The Green's function $G(t, \tau)$ of the main problem 


\section{Example 4.}

Consider the following linear boundary value problem:

$$
\left\{\begin{array}{l}
x^{\prime \prime \prime}-3 x^{\prime \prime}+x^{\prime}-3 x=f(t) \\
x(0)=0, x^{\prime}(0)=0, x^{\prime \prime}(0)=0 .
\end{array}\right.
$$

The function $x(t)$ is given with an error, i.e. $\tilde{x}(t)=x(t)+\varepsilon(t)$. The unknown function $f(t)$ on the right-hand side of the differential equation (11) is required to find. The plot of the unperturbed function $x(t)$ and function of initial data $\tilde{x}(t)$ is shown in Fig. 14 .

The Green's function of the auxiliary and the main problems are found. Their graphs are presented in Fig. 16 and Fig. 17, respectively. Then the solution of the original problem $f(t)$ is found. It is represented in Fig. 15 .

The absolute error of the obtained solution is $\delta_{a}=0,22107$, the relative error is $\delta=20.0 \%$. The optimal regularization parameter is $\alpha=5 \cdot 10^{-7}$. The operating time of the program with the determination of the regularization parameter is $t_{1}=4.2 \mathrm{~min}$. The running time of the program with the specified regularization parameter is $t_{2}=19.1 \mathrm{sec}$.

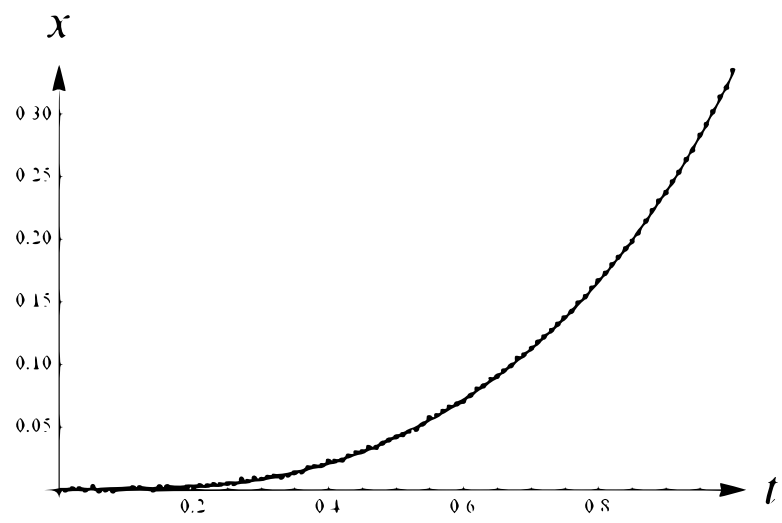

Fig. 14. The exact function of the initial data $x(t)$ (solid), the given perturbed function of the initial data $\tilde{x}(t)$ (points)

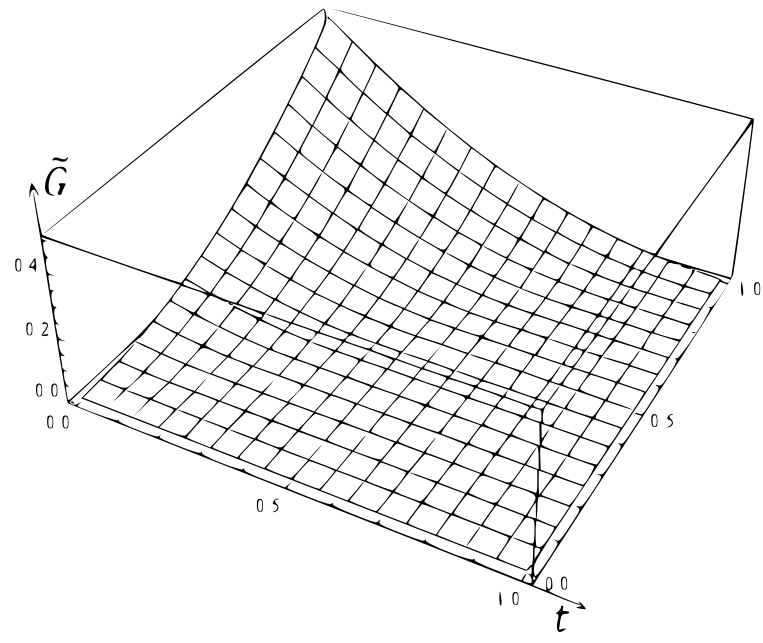

Fig. 16. The Green's function $\tilde{G}(t, \tau)$ of the auxiliary problem

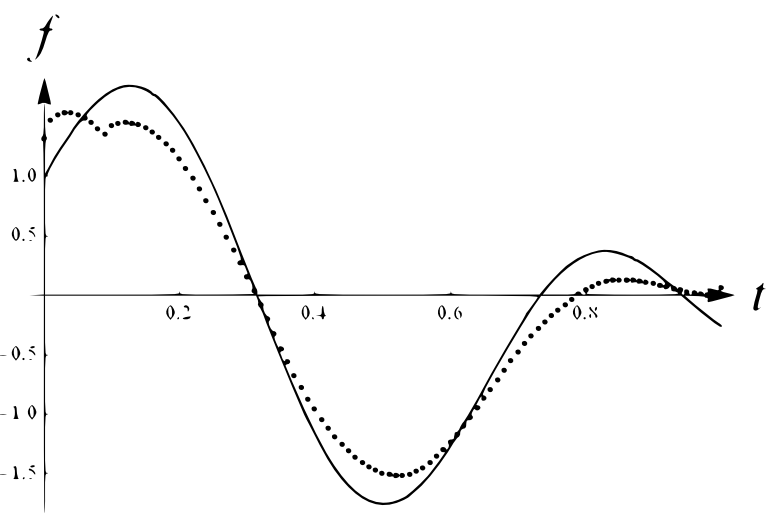

Fig. 15. The exact function of the solution $f_{0}(t)$ (solid), the obtained function of the solution $f(t)$ (points)

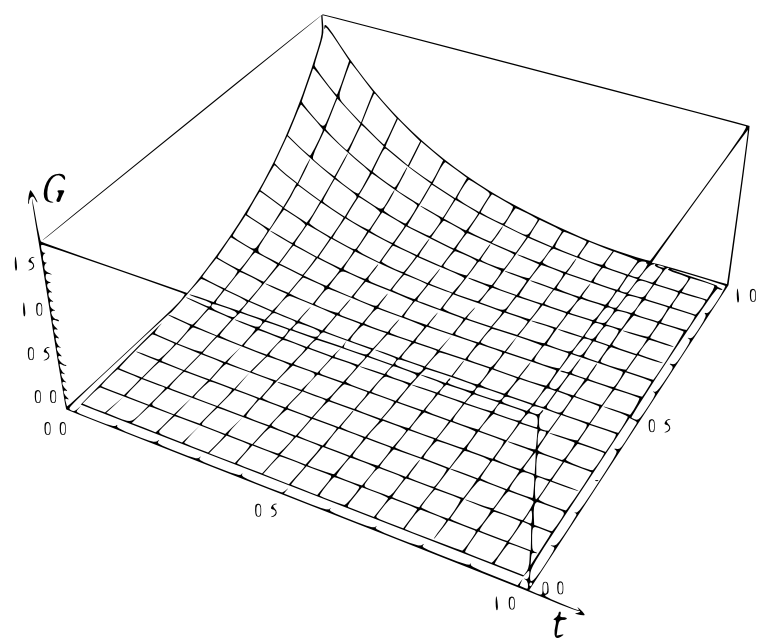

Fig. 17. The Green's function $G(t, \tau)$ of the main problem 


\section{Example 5.}

Consider the following linear boundary value problem:

$$
\left\{\begin{array}{l}
x^{\prime \prime \prime}-5 x^{\prime \prime}+2 x^{\prime}-10 x=f(t) \\
x(0)=0, x(0,5)=0, x(1)=0 .
\end{array}\right.
$$

The function $x(t)$ is given with an error, i.e. $\tilde{x}(t)=x(t)+\varepsilon(t)$. The unknown function $f(t)$ on the right-hand side of the differential equation (12) is required to find. The plot of the unperturbed function $x(t)$ and function of initial data $\tilde{x}(t)$ is shown in Fig. 18.

The Green's function of the auxiliary and the main problems are found. Their graphs are presented in Fig. 20 and Fig. 21, respectively. Then the solution of the original problem $f(t)$ is found. It is represented in Fig. 19.

The absolute error of the obtained solution is $\delta_{a}=0.113366$, the relative error is $\delta=11,0 \%$. The optimal regularization parameter is $\alpha=10^{-8}$. The operating time of the program with the determination of the regularization parameter is $t_{1}=5.3 \mathrm{~min}$. The running time of the program with the specified regularization parameter is $t_{2}=59.8$ sec.

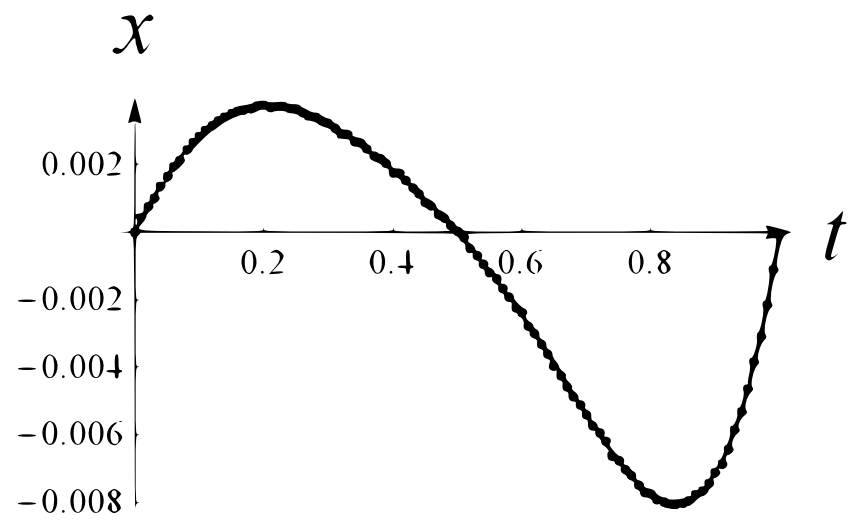

Fig. 18. The exact function of the initial data $x(t)$ (solid), the given perturbed function of the initial data $\tilde{x}(t)$ (points)

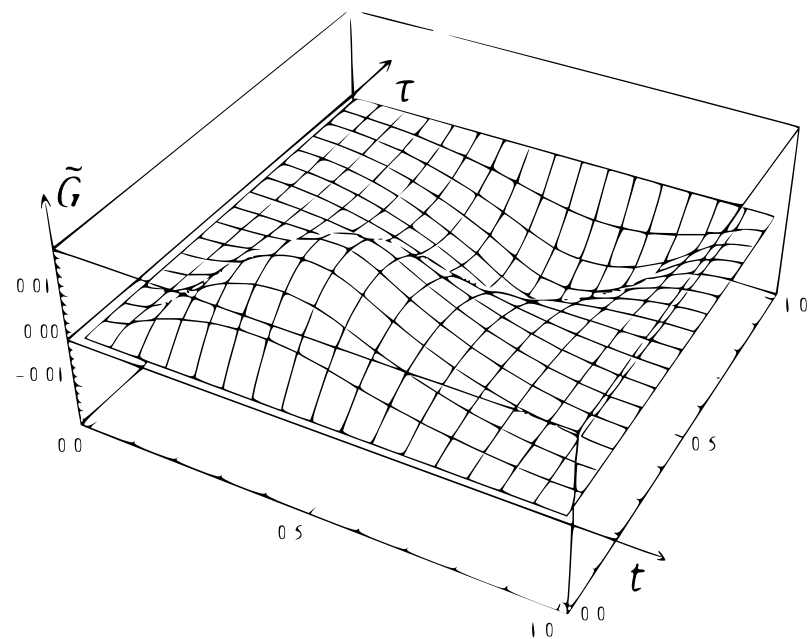

Fig. 20. The Green's function $\tilde{G}(t, \tau)$ of the auxiliary problem

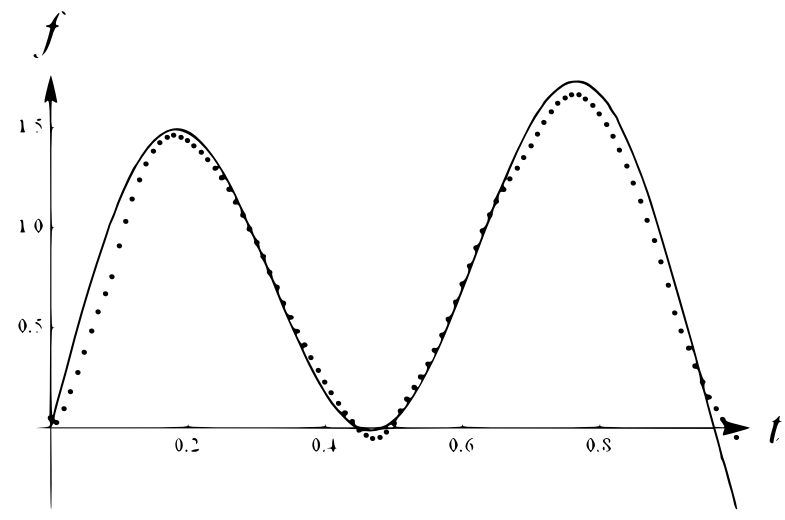

Fig. 19. The exact function of the solution $f_{0}(t)$ (solid), the obtained function of the solution $f(t)$ (points)

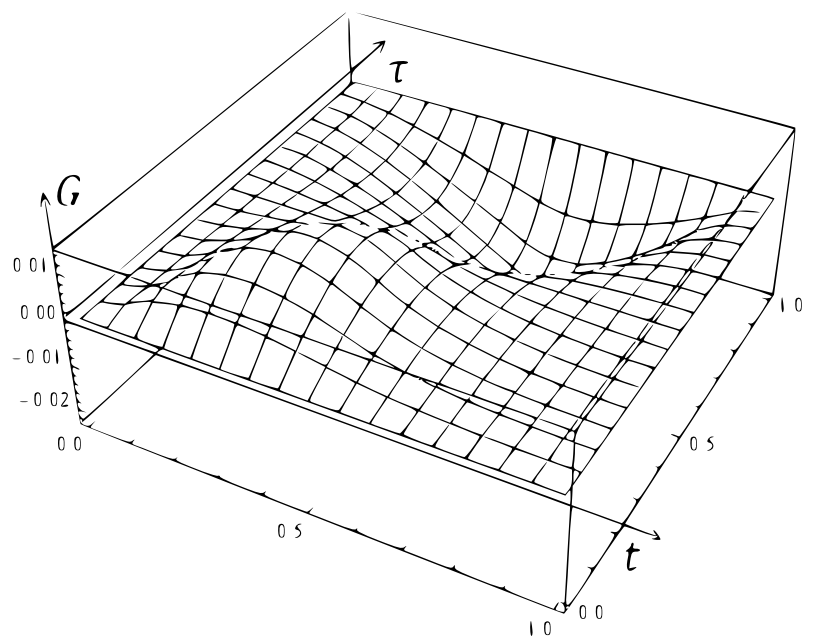

Fig. 21. The Green's function $G(t, \tau)$ of the main problem 
Example 6. Consider the following linear boundary value problem:

$$
\left\{\begin{array}{l}
x^{\prime \prime \prime}-2 x^{\prime \prime}+3 x^{\prime}-6 x=f(t) \\
\int_{0}^{1} x(t) d t=0, \int_{0}^{1} t x(t) d t=0, \int_{0}^{1} t^{2} x(t) d t=0 .
\end{array}\right.
$$

The function $x(t)$ is given with an error, i.e. $\tilde{x}(t)=x(t)+\varepsilon(t)$. The unknown function $f(t)$ on the right-hand side of the differential equation (13) is required to find. The plot of the unperturbed function $x(t)$ and function of initial data $\tilde{x}(t)$ is shown in Fig. 22 .

The Green's function of the auxiliary and the main problems are found. Their graphs are presented in Fig. 24 and Fig. 25, respectively. Then the solution of the original problem $f(t)$ is found. It is represented in Fig. 23.

The absolute error of the obtained solution is $\delta_{a}=0.207377$, the relative error is $\delta=13.2 \%$. The optimal regularization parameter is $\alpha=10^{-7}$. The operating time of the program with the determination of the regularization parameter is $t_{1}=4 \mathrm{~min}$. The running time of the program with the specified regularization parameter is $t_{2}=34 \mathrm{sec}$.

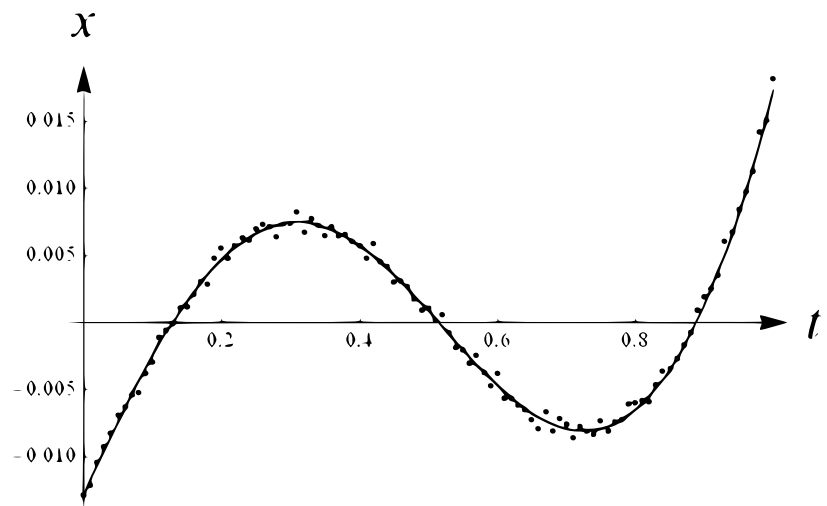

Fig. 22. The exact function of the initial data $x(t)$ (solid), the given perturbed function of the initial data $\tilde{x}(t)$ (points)

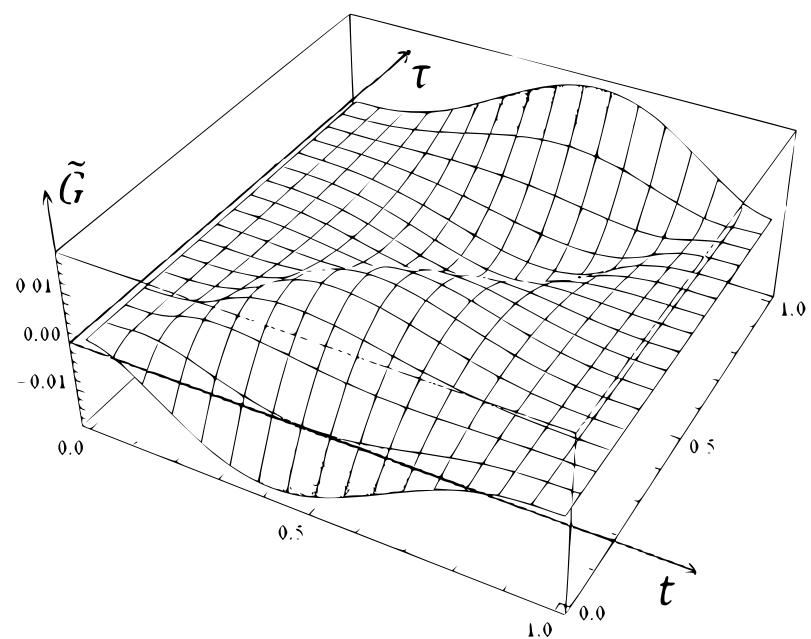

Fig. 24. The Green's function $\tilde{G}(t, \tau)$ of the auxiliary problem

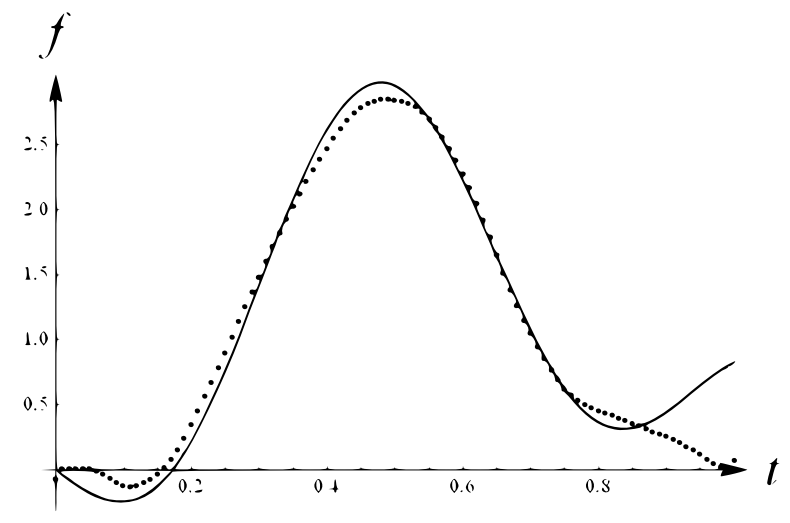

Fig. 23. The exact function of the solution $f_{0}(t)$ (solid), the obtained function of the solution $f(t)$ (points)

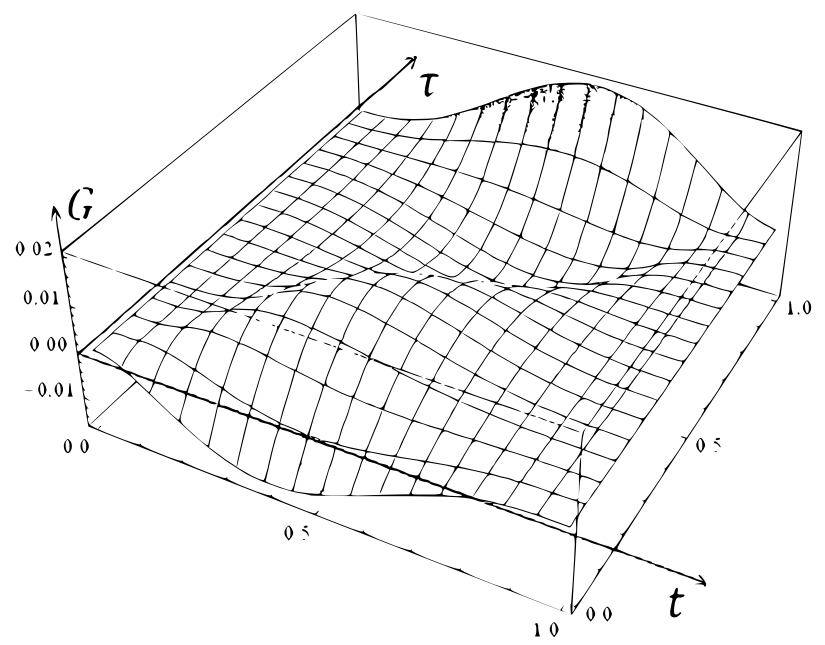

Fig. 25. The Green's function $G(t, \tau)$ of the main problem 


\section{References}

1. Granovsky V.A. Dynamic Measurements: The Basics Metrological Support. Leningrad, Energoatomizdat Publ., 1984.(in Russian)

2. Shestakov A.L. Methods of the Theory of Automatic Control in Dynamic Systems. Chelyabinsk, Publishing center of SUSU, 2013. (in Russian)

3. Sergienko A. B. Digital Signal Processing. St. Petersburg, Piter Publ., 2002. (in Russian)

4. Asfandiyarova Yu.S. The Inversion Procedure for Ordinary Differential Equation's Linear Boundary Problem. Bulletin of the South Ural State University. Series: Mathematics. Mechanics. Physics, 2011, № 32 (249), issue 5, pp. 12-17. (in Russian)

5. Tikhomirov V. M. Some Questions of Approximation Theory. Moscow, Publisher of Moscow University, 1976. (in Russian)

6. Naimark M. A. Linear Differential Operators. Moscow, Nauka Publ., 1969. (in Russian)

7. Ivanov V. K., Vasin V. V., Tanana V. P. Theory of Linear Ill-Posed Problems and its Applications. Moscow, Nauka Publ., 1978. (in Russian)

8. Zalyapin V.I., Kharitonova H.V., Ermakov S.V. Inverse Problems of the Measurements Theory. Inverse Problems, Design and Optimization Symposium. Miami, Florida, U.S.A., 2007, pp. 91-96.

9. Asfandiyarova Yu.S., Zalyapin V.I., Kharitonova Ye.V. The Method of the Integral Equations to Construct the Green's Function. Bulletin of the South Ural State University. Series: Mathematical Modelling, Programming \& Computer Software, 2012, no. 27 (286), issue 13, pp. 16-23. (in Russian)

10. Zalyapin V.I., Popenko Yu.S., Kharitonova H.V. Error Estimate of Numerical Method for Solving an Inverse Problem Bulletin of the South Ural State University. Series: Mathematical Modelling, Programming \& Computer Software, 2013, vol. 6, no. 3, pp. 51-58. (in Russian)

11. Asfandiyarova Yu.S. [Numerical Analysis of one Inverse Problem for Linear Differential Equations] Works of the Mathematical Center N.I. Lobachevsky. Kazan, Kazan Mathematical Society, 2010, vol. 40, pp. 32-36. (in Russian)

Yuliya S. Popenko, Department of Mathematical Analysis and Methods of Mathematics Teaching, South Ural State University (Chelyabinsk, Russian Federation), popenkoyu@mail.ru

Received April 12, 2017 


\title{
ОБ ОДНОМ ЧИСЛЕННОМ МЕТОДЕ РЕШЕНИЯ ПРЯМЫХ И ОБРАТНЫХ ЗАДАЧ ТЕОРИИ ДИНАМИЧЕСКИХ ИЗМЕРЕНИЙ
}

\author{
Ю. С. Попенко
}

\begin{abstract}
В работе рассматриваются прямые и обратные задачи теории динамических измерений на основе линейных краевых задач для обыкновенных дифференциальных уравнений с граничными условиями различного типа. Рассмотрен линейный дифференциальный оператор и система граничных условий, являющихся линейными и линейно-независимыми функционалами (включая задачу Коши, двухточечную краевую задачу, задачу Валле-Пуссена, многоточечные краевые задачи, задачи с распределенными данных и т.д.). Предложен подход к исследованию таких задач на основе математических моделей, реализованных в форме линейных краевых задач и сопутствующих интегральных уравнений, использующий функцию Грина. Функции Грина, в случае отсутствия информации о фундаментальной системе решений соответствующего дифференциального уравнения, строится как решение интегрального уравнения Фредгольма второго рода. Характеристики уравнения Фредгольма определялись функцией Грина вспомогательной задачи. Предлагаемый метод позволяет решать как прямую (задачу нахождения решений), так и обратную (задачу о нахождении правой части уравнения из экспериментально полученного решения). В работе приводятся примеры работы программ реализованных в системе Mathematica 8.0 на основе описанного метода.

Ключевые слова: функиия Грина, нелокальные граничные условия, теория измерений, динамические измерения.
\end{abstract}

\section{Литература}

1. Грановский, В.А. Динамические измерения: Основы метрологического обеспечения / В.А. Грановский. - Л.: Энергоатомиздат, 1984.

2. Шестаков, А.Л. Методы теории автоматического управления в динамических системах: монография / А.Л. Шестаков. - Челябинск: Издательский центр ЮУрГУ, 2013.

3. Сергиенко, А.Б. Цифровая обработка сигналов / А.Б. Сергиенко. - СПб.: Питер, 2002.

4. Асфандиярова, Ю.С. Об одном способе обращения линейных задач для обыкновенных дифференциальных уравнений / Ю.С. Асфандиярова // Вестник ЮжноУральского государственного университета. Серия: Математика. Механика. Физика. - 2011. - № 32 (249), вып. 5, - С. 12-17.

5. Тихомиров, В.М. Некоторые вопросы теории приближений / В.М. Тихомиров М.: Издательство московского университета, 1976.

6. Наймарк, М.А. Линейные дифференциальные операторы / М.А. Наймарк. М.: Наука, 1969.

7. Иванов, В.К. Теория линейных некорректных задач и ее приложения. / В.К. Иванов, В.В. Васин, В.П. Танана. - М.: Наука, 1978. 
8. Zalyapin, V.I. Inverse Problems of the Measurements Theory / V.I. Zalyapin, H.V. Kharitonova, S.V. Ermakov // Inverse Problems, Design and Optimization Symposium. - Miami, Florida, U.S.A., 2007. - P. 91-96.

9. Асфандиярова, Ю.С. Метод интегральных уравнений построения функции Грина / Ю.С. Асфандиярова, В.И. Заляпин, Е.В. Харитонова // Вестник ЮжноУральского государственного университета. Серия: Математическое моделирование и программирование. - 2012. - № 27 (286), вып. 13. - С. 16-23.

10. Заляпин, В.И. Оценка погрешности численного метода решения одной обратной задачи / В.И. Заляпин, Ю.С. Попенко, Е.В. Харитонова // Вестник ЮжноУральского государственного университета. Серия: Математическое моделирование и программирование. 2013. - № 6, Т. 3. - С. 51-58.

11. Асфандиярова, Ю.С. Численный анализ одной обратной задачи для линейного дифференциального уравнения / Ю.С. Асфандиярова // В кн. Труды Математического центра им. Н.И. Лобачевского. - Казань: Казан. матем. общ-во, 2010. T. $40 .-$ C. $32-36$.

Попенко Юлия Сагитовна, кафедра математического анализа и методики преподавания математики, Южно-Уральский государственный университет (г. Челябинск, Российская Федерачия), рорепkоуи@таil.ru

Поступила в редакиию 12 апреля 2017 г. 